\title{
La formación universitaria y la sensibilidad humana de frente al futuro
}

University Education and Human Sensitivity for the Future

\section{Freddy Varona Domínguez*}

(D) https://orcid.org/0000-0002-5214-2735

Tipo de Artículo: Informes de Investigación y ensayos inéditos

Doi: 10.17533/udea.unipluri.20.2.023

Varona Domínguez, F. (2020). La formación universitaria y la sensibilidad humana de frente al futuro. UniPluriversidad, 20(2). e20202023. doi: 10.17533/udea.unipluri.20.2.023

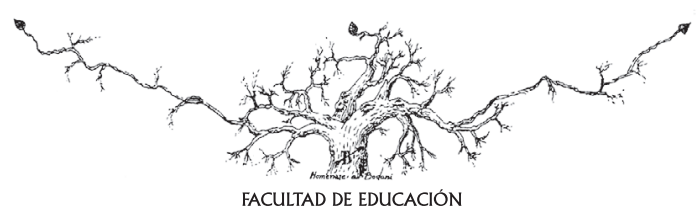

Recibido: 2020-02-23 • Aprobado: 2020-12-22

* Universidad de la Habana, Cuba.

Email: fvarona1960@gmail.com 


\title{
Resumen
}

El razonamiento que se expone en este trabajo se enmarca en la filosofía de la educación. Este estudio se desarrolló mediante la metodología documental, dada por el análisis crítico de textos y de información escrita, apoyado en principios del pensamiento complejo: complejidad versus simplificación, integración, y lucha contra el reduccionismo y la disyunción. Sus categorías básicas son formación universitaria, sensibilidad humana e indiferencia a través de las cuales salieron a relucir dos asuntos de gran actualidad, aparentemente carentes de vínculos entre sí, que llegan a tomar consistencia de tareas apremiantes en el quehacer con los futuros profesionales universitarios: la formación activa e integradora y el ataque a la indiferencia. Las reflexiones acerca de estos temas mostraron que entre ambos hay un aspecto común, la sensibilidad humana. De esta categoría se expone una elaboración teórica original y se destaca su importancia en la sociedad humana actual y en la formación universitaria.

Palabras clave: sensibilidad humana; formación universitaria; formación activa e integradora; indiferencia; razón; afectividad.

\begin{abstract}
The reasoning that is exposed in this work is part of the philosophy of education. This study was developed through a documentary methodology which is given by the critical analysis of texts and written information, and it is supported by principles of complex thinking: complexity versus simplification, integration, and the fight against reductionism and disjunction. Basic categories of the study are university formation, human sensitivity and indifference through which two highly topical issues arose, apparently unrelated to each other, and made for a consistency as urgent tasks in the work with future professionals in training: active and integrating training and attacking indifference. Reflections on these issues evidenced a common aspect, human sensitivity. An original theoretical elaboration about this category is presented and its relevance in both current human society and university education is highlighted.
\end{abstract}

Keywords: human sensitivity; University education; active and inclusive training; indifference; reason; affectivity. 


\section{INTRODUCCIÓN}

A inicios de la tercera década de la centuria veloz es imposible empezar alguna reflexión sin hacer alusión al terrible problema que tiene hoy la humanidad: la pandemia covid-19, que ha alterado toda su vida y le ha mostrado acusatoriamente que aunque lleva alrededor de medio siglo luciendo con gran orgullo asombrosos logros de la ciencia y la tecnología, que se incrementan cada vez con mayor celeridad y más elevada sofisticación, todavía la fragilidad la acompaña, evidenciada en la falta de preparación para enfrentar una emergencia de esa magnitud, que había sido imaginada, quizás, solo por muy pocas personas.

Hoy, además de lamentar la cósmica cantidad de fallecidos a causa de esa enfermedad y las secuelas, aun por investigar, para hallarle remedio efectivo y evitarlas, ante el ser humano pende con urgencia la tarea de prepararse para eventualidades similares o peores y, en tales circunstancias, por lo menos, no carecer de medicamentos, recursos e instalaciones para enfrentar avalanchas de damnificados. La humanidad tiene que aprender de este fenómeno y afianzar la solidaridad internacional, aunque parece que tendrá que recibir muchos más golpes como este antes de entender que es preciso realizar cambios a nivel mundial.

Desde finales del siglo pasado y a escala internacional, es perenne la referencia al conocimiento y, por extensión, con significativo énfasis se hace alusión a todo cuanto se relaciona con él. En correspondencia, se subraya de muchas maneras la formación universitaria; esto sucede ante todo por dos causas: primero, esta faena se relaciona ac- tiva y crecientemente con el consumo, almacenamiento y difusión del conocimiento, pero sobre todo con su producción; segundo, todo este proceso tiene nexos directos y básicos con la tarea que constituye la razón de ser, esencia y finalidad básica de la formación universitaria: dar a luz profesionales con elevada preparación que los haga capaces en el futuro de participar, de una u otra manera, en el funcionamiento de la sociedad en sus diversos niveles y esferas, así como de cumplir la responsabilidad de realizar la mencionada cadena de elaboraciones mentales y acciones que abarca producir el conocimiento, diseminarlo, conservarlo y, muy importante, darle el uso que ha de poseer las características deseadas hoy con insistencia: diversidad, amplitud, profundidad $\mathrm{y}$, sobre todo, rapidez y (como corona) eficiencia.

La creciente atención que se brinda al conocimiento (con una considerable cobertura por los medios de comunicación masiva) no puede conducir a que en el quehacer formativo universitario solo se piense en los temas propios de una especialidad y en la capacidad racional para procesar la información; esto conduciría a una parcialización de la formación universitaria y a un reduccionismo de la misma, que traería como consecuencia profesionales limitados, aun cuando sean geniales poseedores del saber propio de la carrera en la cual se formaron. De ahí la importancia de prestarle mayor atención a una categoría en la cual debe pensarse más: sensibilidad humana.

La sensibilidad ha sido tratada de muchas maneras, desde diversas perspectivas $y$ en el marco de varias especialidades: fi- 
losofía, psicología, sociología, entre otras. Por lo general, ha estado relacionada con el conocimiento, por eso ha sido común la óptica epistemológica en su estudio, mas, en el presente trabajo, sin alejarse totalmente de esta connotación, se persigue destacar la parte del ser humano que ha solido presentarse como opuesta a la razón. De ese modo, se habla de la sensibilidad humana, aunque con ella se persigue no solo reconocer la importancia de los sentimientos, las emociones y las pasiones, sino, a su vez, la reacción de los seres humanos desde todo este conjunto de cualidades y capacidades humanas.

En la focalización de este asunto, en el desarrollo de la mencionada categoría y en la decisión de tratarlo en algún artículo, intervino de manera cardinal el hecho de que no obstante la importancia que actualmente tiene el conocimiento y lo tanto que se habla de él por todas partes, en las aulas universitarias tiene lugar un fenómeno que, según parece, todavía no tiene dimensiones para considerarlo un asunto problemático, pero se va acentuando moderadamente y quizás, al pasar el tiempo, se transforme en un problema científico digno de investigar y, quien quita que entonces tenga que hacerse con urgencia, se trata del aumento de la cantidad de estudiantes insensibles. No es que se esté hablando solo de indolencia al contenido docente, de lo cual pudiera pensarse de manera superficial en varias causas: la carrera lo ha decepcionado, la seleccionó bajo alguna presión, continúa estudiando por obligación, cambiaron sus intereses, entre muchas más; tampoco es que la reflexión se haya motivado por la desidia al arte, a la belleza o a las normas consideradas de alta educación. ¡No! Lo inquietante es que en las aulas universitarias hay cada vez mayor cantidad de estudiantes indiferentes a todo, a cuanto acontece a su alrededor, incluso, a sus compañeros de carrera.
El fenómeno de la indiferencia ha preocupado a más de un autor (Bodei, 1995; Cruz, Pérez, Torralba y Bonilla 2017; Nieto y Somuano, 2020) y le han prestado atención con ópticas muy disímiles. Una de las afirmaciones resultante de reflexiones en torno a esta temática, ciertamente un tanto categórica, se centra en que "los seres humanos han perdido el asombro ante la mágica presencia del otro, ante la sonrisa y la mirada de esos otros, ante el atardecer y el cielo estrellado" (García, 2018, p. 11).

Esa situación lleva a pensar en qué potencialidades tiene la formación universitaria para actuar sobre ese fenómeno y evitar el incremento de profesionales que se muestren a los ojos de la sociedad con una desesperante indiferencia a lo que está a su alrededor. Ahora bien, cuanto se pueda imaginar y pretender con esta labor ha de realizarse con amplitud mental, deseo innovador, paciencia y un optimismo de magnitudes quiméricas. No caben dudas de que el tema no se va a agotar en una investigación y, en cambio, hay certeza en cuanto a que se necesita un trabajo teórico grande, sostenido, con reflexiones diversas, encontradas y provocadoras de debates, donde se gesten recomendaciones prácticas y se formulen soluciones óptimas. El presente trabajo es incitador; tiene, de manera subyacente, la pretensión de invitar a pensar en el asunto, a polemizar, incluso a errar en el intento de hallar soluciones. Lo importante es no permitir la existencia de indiferentes a la indiferencia.

El presente trabajo es de corte filosófico y se realiza desde la especialidad que se ha dado en llamar filosofía de la educación. De este modo, se caracteriza por ir a la esencia del fenómeno, por su nivel de abstracción, su grado de universalidad y generalización teóricas y por posicionarse en las relaciones entre el ser y el deber ser. Estos nexos 
complejos toman concreción mediante los vínculos entre las categorías formación universitaria y sensibilidad humana, aunque se usa otra: indiferencia; estas se observan en el corriente siglo XXI y a escala global.

Este artículo se enmarca en el ámbito académico superior o universitario, de ahí el empleo de la categoría formación universitaria, de la cual se subrayan dos características como esenciales por la importancia que se les concede en función del tema de referencia: activa e integradora. La primera está dada por el rol protagónico del estudiante en su formación como profesional, lo cual significa que debe ser capaz, de manera independiente y creativa, de profundizar sus conocimientos y diversificarlos, tanto como de resolver problemas. La segunda, por su parte, consiste en la integración de sus facultades humanas que existen de esa manera, aunque se ha hecho común, consciente o inconscientemente, separarlas y verlas separadas.

Sobre esa base, en estas reflexiones tiene un lugar central la categoría sensibilidad humana, con la elaboración teórica del autor, quien ha modificado su significado común, y se exponen algunas consideraciones en torno a la lucha contra la indiferencia en el marco de la formación universitaria. Se enfatiza en que este asunto hay que encararlo con creatividad e imaginación, así como con la conjugación de las capacidades humanas, entre ellas la razón y la afectividad.

El objetivo del presente trabajo es argumentar por qué, de cara al porvenir, debe haber nexos fuertes entre la formación universitaria y el despliegue de la sensibilidad humana. Tiene dos propósitos prácticos: estimular a los formadores universitarios a mirar la formación universitaria de una manera activa e integradora e invitarlos a pensar en el despliegue de la sensibilidad humana en su quehacer formativo universitario.

Este estudio se desarrolló mediante la metodología documental, dada por el estudio crítico de textos y el análisis de información escrita (Matías y Fernández, 2018). La investigación que dio lugar a este texto se desarrolló desde la perspectiva metodológica del pensamiento complejo (Morin, 1999), específicamente en cuanto a la atención esmerada a la complejidad de las relaciones, la integración y la oposición al reduccionismo, la disyunción, el absolutismo y el dogmatismo disfrazado de saber.

Bibliografía empleada: En su mayoría proviene de textos de autores cubanos y de otros países latinoamericanos, muchos de ellos publicados de forma reciente, aunque también hay otros que son clásicos, sobre todo en lo que respecta a la concepción del ser humano.

\section{DesarRollo}

\section{Una ubicación teórica oportuna}

Los resultados en el ámbito académico dependen en gran medida de la concepción que se tenga acerca de la formación. La importancia de esta categoría es básica y está dada porque desde ella se establecen los principios del quehacer formativo, se instituye los derroteros a seguir y se formulan los objetivos a lograr; por ello, es preciso estudiarla con una hondura creciente y, a su vez, contribuir al aumento de su precisión y desarrollo teóricos y al incremento de la claridad de su alcance práctico. 
En la bibliografía especializada no faltan textos donde la categoría se emplea sin una mínima definición (Duarte y Valbuena, 2014), de tal modo, el significado con el cual se usa se debe deducir del contenido y este, no pocas veces, conduce a entenderlo en relación con el hecho de dotar a las personas de conocimientos que las preparen para alguna función social específica (Bisquerra, 2005), o en cuanto al desarrollo de determinadas características profesionales o humanas generales, o sea, cualidades: conocimientos, manejo de las emociones, comunicación, entre otras, con la finalidad expresa de que se empleen y manifiesten en acciones concretas (Cuervo, 2017; Pérez, 2018).

Por lo general, cuando la formación se observa desde la perspectiva académica, se concibe mediante el proceso docente-educativo y como una parte constitutiva suya, que puede verse por áreas, por ejemplo, formación política, económica, jurídica, etc. (Ramos, 2006) y por profesiones, por ejemplo, profesoral, médica, jurídica, en todos los casos ligada a la adquisición de nuevos conocimientos y a la reacomodación de los existentes (Zabalza, 2011). Así, la formación también se asocia al conocimiento de la especialidad que se imparte y a las competencias que sus profesionales deben tener. En esas circunstancias no falta la atención a lo educativo y lo didáctico (Vázquez, 2014; Martins, 2014; Velásquez, 2016) y a la consideración de que la formación es objeto de la pedagogía; esta última se concibe como un campo centrado en la educación y la formación (Loaiza-Zuluaga, Taborda-Chaurra y Ruiz-Ortega, 2020), por lo cual, ambas se ven estrechamente relacionadas y con fronteras muy tenues, situación que conduce a algunos autores a usarlas indistintamente en un mismo texto (Montañez y Suárez, 2019). Aparte de todas estas opiniones y de otras diferentes que puedan citarse, un rasgo básicamente distintivo de la formación es que se realiza con la participación consciente de quien se está formando.

Al utilizarse en el entorno académico, la categoría formación tiene una serie de características, entre ellas: primero, la amplitud, que, si ciertamente la complica sobremanera, también la dota de grandes posibilidades teóricas y de un alcance práctico diverso y de extraordinaria extensión; segundo, por lo general, se conjugan en ella la educación y la instrucción con el fin de destacar que con ella se persigue moldear a los seres humanos y, simultáneamente, dotarlos de conocimientos; tercero, se realiza con la participación consciente de quien se está formando; y cuarto, su esencia consiste en llegar a crear en los estudiantes algo nuevo, superior a lo existente, o por lo menos igual a la calidad más elevada que se ha alcanzado hasta el momento.

Cuando la formación sobrepasa los vastos fines académicos, aun manteniéndose en el marco propio de la academia, y arriba a la amplitud consustancial al ser humano, deviene formación humana. En este caso "se asienta en el objetivo de formar seres humanos" (Pacheco y Pupo, 2017, p. 52), algo posible solo si se tiene en cuenta la complejidad del ser humano. Sobre esta base, la formación puede rebasar los límites de los objetivos de una profesión o de un área social específica y tener en cuenta no solo el desarrollo intelectual y profesional del futuro egresado, sino también atender su afectividad, educarla, desarrollarla. Aquí prevalece el propósito de desarrollar armónicamente a los seres humanos, para que sean capaces de pensar y de hacerlo con independencia, creatividad y solidez ética, para que estén aptos para captar lo verdadero y lo bueno, pero también para percibir lo bello y disfru- 
tarlo en la mayor plenitud posible, sin que por ello se ignore o menosprecie la fealdad, sino que se aprecie en una medida justa.

Algo cercana a esa manera de ver la categoría de referencia es la denominada socioformación, cuyo núcleo son los retos sociales y ambientales, así como las necesidades de autorrealización personal; su intención es que las personas aprendan a identificar, interpretar, argumentar y resolver problemas de manera colaborativa, con un proyecto ético de vida, así como que desarrollen su capacidad de emprendimiento. La amplitud de este espíritu se observa en que, según esta modalidad, la formación se entiende como un quehacer donde se involucran, al mismo tiempo, más de una disciplina docente (Balladares, Avilés y Pérez, 2016; Vázquez, Hernández, Vázquez-Antonio, Juárez y Guzmán, 2017).

¿Qué entender por la categoría de referencia en el ámbito académico? La formación como categoría académica es un sistema y un proceso, constituido por relaciones de diversas índoles, que pueden observarse en etapas y niveles, siempre matizadas por las condiciones histórico-sociales concretas y por los nexos entre el accionar externo a cada individuo y su universo espiritual (la capacidad racional y la afectividad, con los resultados de cada una y sus vínculos mutuos), aunque su rasgo identificador es que el rol determinante en ella lo tiene la conciencia de quien se está formando y su subjetividad: convicciones, aspiraciones, propósitos, ideales, que son impulsos para vencer obstáculos, alcanzar metas y rebasarlas.

Desde ese modo de entender la formación es evidente la importancia del protagonismo de quien se está formando. Esta es una premisa insoslayable no solo para hablar de formación, sino para sostener el propósi- to de lograr la existencia de un profesional universitario multilateralmente desarrollado, propósito que se corresponde con la idea de una formación universitaria con la cual se tiene en cuenta la complejidad de la vida.

Hoy, mucho más que en tiempos pasados, los conocimientos y las habilidades no bastan para que los profesionales se desempeñen con éxito en su profesión; la sociedad actual requiere una mirada integradora, apertura mental y racionalidad flexible y esas cualidades deben estar presentes en los profesionales que vivan en ella y la desarrollen. De aquí que autores como Cuadra-Martínez, Castro y Juliá (2018) enfaticen el desarrollo integral de los estudiantes y que lo vean como un aprendizaje complejo, porque "requiere de la integración en el aprendiz de saberes científicos, cotidianos y profesionales, en un mismo escenario de formación y posterior ejercicio profesional" (p. 20). De aquí también la importancia de la formación integral, cada vez más amplia y abarcadora, que se despliegue con una visión compleja y dúctil, que, teniendo en cuenta las potencialidades de los individuos, sus iniciativas y autonomía, se encamine a integrar conocimientos, habilidades profesionales y valores y así proporcionar un desempeño profesional eficiente, con sólido sustento ético y marcado compromiso social.

Aunque no con la cantidad suficiente, puede hallarse voces por todo el mundo que aclaman por la formación integral de los estudiantes que traiga como resultado profesional que, además de dominar los conocimientos científicos, sean sensibles a los problemas de la sociedad y así vinculen su profesión y la transformación social (Ronquillo, Cabrera y Barberán, 2019).

Una de las necesidades básicas de la sociedad actual es desarrollar el pensamiento 
crítico y creativo en niveles superiores. Esta faena exige grandes y profundas transformaciones en la mentalidad de las personas, tarea sumamente difícil que lleva tiempo y mucha paciencia; con ella no surgen automáticamente cambios en el discurso y el comportamiento, antes bien, hace falta una labor específicamente encaminada a realizar estos propósitos, que en la formación universitaria pueden lograrse en gran medida mediante los diálogos y la actitud crítica y emancipadora de los profesores (Díaz, 2013), tanto como descentrada.

El modo de entender la formación puede ser integral o fraccionado, con amplitud o estrechez; en ello es básica y esencial la concepción acerca del ser humano que le sirve de fundamento al quehacer formador.

En las concepciones acerca de los humanos sobresale la visión según la cual se hace de una especificidad humana el centro de dicha concepción y, automáticamente, se convierte a esa especificidad en lo esencial y definitorio del ser humano. Tal es el caso de la razón (Descartes, 2011), los sentimientos (Rousseau, 2011), el conjunto de relaciones sociales (Marx, 1973), la capacidad de pensar en Dios (Ruiz, 1955), el nexo biosocial (Minkevicius, 1988), la imaginación (Lapoujade, 1988).

Es innegable que, con esa forma simplificadora, propia del pensamiento simplificador, oriundo y típico de la Modernidad, la humanidad tuvo grandes resultados, sin embargo, el desarrollo actual de los conocimientos científicos y tecnológicos exige un modo de pensar diferente, que no simplifique ni fraccione, sino que sea complejo, entre cuyos rasgos está ser integrador (Morin, 2012), con lo cual responde a los desafíos de dichos conocimientos (Maldonado, 1999). Con esta modalidad se comprende al ser humano como un todo complejo, cuya esencia está en la bipolarización de caracteres antagónicos (Morin, 1999) y sus facultades y características se conciben de forma integrada. Desde esa perspectiva se consolida la tendencia a justipreciar lo racional y lo afectivo como componentes humanos, fin que se trata de realizar mediante la categoría sensibilidad humana.

La palabra sensibilidad tiene varias acepciones. Una de ellas refiere la facultad de sentir, propia de los seres vivos, que en el caso de los humanos no es algo dado inmediatamente, sino una superación de lo biológico, porque sus sentidos son frutos de la actividad, sobre todo la práctica, donde se desarrollaron propiedades humanas y se enriqueció la conciencia sensible. Otra alude a la cualidad propia de cuanto tiene la facultad de sentir, experimentar sensaciones, que en los humanos pueden ser físicas o morales y producen sentimientos que, en este caso, según sea la perspectiva desde donde se observe, puede hablarse de sensibilidad política, ecológica, artística, estética. Entre sus significados puede hallarse otros dos: refiere la tendencia natural humana a dejarse llevar por la compasión, la piedad, la ternura, así como el comportamiento que se desprende de ellas; expresa la propiedad de los seres humanos para manifestarse de alguna manera: atracción o rechazo, aun cuando los estímulos sean sumamente pequeños y aparentemente insignificantes.

Esa última acepción es la base donde toma consistencia la categoría sensibilidad humana. Con ella en el presente trabajo se tiene en cuenta lo siguiente: urge darle mayor atención a la integración de la razón y la afectividad (sentimientos, emociones, pasiones); en dicha integración, para logar equilibrio, se debe priorizar la afectividad; 
todos los estímulos son importantes, aunque sean mínimos; ante los estímulos debe haber respuestas y atenderse.

En la categoría sensibilidad humana, el adjetivo significa no solo que pertenece a los humanos, sino que contiene una finalidad humanamente constructiva verbal y de acción, por lo cual es antítesis de la indiferencia y la pasividad; no bastan la piedad y la ternura, es imprescindible la solución de los problemas; su espíritu es marcadamente tolerante y comprensivo para no desencadenar violencia, sino solidaridad y ayuda.

Esta concepción de sensibilidad huma$n a$ tiene entre sus antecedentes el concepto razón poética, de la filósofa española María Zambrano (1904-1991), que ha despertado la atención de más de un estudioso (García, 2014). La filósofa sostuvo dicho concepto para referir la integración de la razón y los sentimientos como vía para enfrentar los problemas del mundo que le tocó vivir (1939, p. 20).

Entre la razón poética y la sensibilidad humana hay un punto común: la integración de la razón y la afectividad, pero en la sensibilidad humana la pretensión integradora se encamina a destacar la importancia de todo estímulo y de las reacciones, con la finalidad de atacar la indiferencia y estimular el incremento y la diversificación de los intereses de los seres humanos. La afectividad posee gran importancia en la formación universitaria. Esto no puede interpretarse de ninguna manera como que la razón se relegue a un plano secundario o que no se despierte en los alumnos el razonamiento. Lo que se persigue es aunarlas y aumentar el poderío de los seres humanos con esa unidad (los estudiantes, en este caso) en su propio beneficio, propósito que lleva implícita la estimulación del interés por transformar la sociedad y construir una mejor, lo cual significa que sea más humana. De este modo, se impulsa a los futuros profesionales a no ser indiferentes, a ser impetuosos y a comprometerse con la solución de los problemas, sobre todo los sociales.

Esa posición de principio ha de estar enlazada a la realización de actividades prácticas, pues a través de ellas los estudiantes entran en un contacto mayor y más profundo con la transformación del mundo, con lo cual sale a la luz la capacidad transformadora de la formación universitaria y de la sensibilidad humana. El estudiante debe conocer su entorno social no solo para tener conocimientos acerca de él, sino también para transformarlo; este es un modo de evitar la proliferación de profesionales indiferentes.

\section{La formación universitaria activa $e$ integradora}

La sociedad necesita profesionales capaces, óptimos, con una preparación cada vez mayor y que continuamente se acerque más a los máximos niveles de excelsitud, pero tales exigencias quedan incompletas si no se forman como profesionales íntegros $\mathrm{y}$, de este modo, activos socialmente. Una vía para ello es lograr que los estudiantes universitarios tengan en su formación un rol activo. En la realización de este propósito puede traer resultados significativos la estimulación de la búsqueda de conocimientos, pero no se trata simplemente de localizar información; lo significativo es, primeramente, que sea una búsqueda pensada por el profesor, no improvisada, y que sea pensada significa que estimule a los estudiantes a profundizar en un contenido, los inquiete a ir siempre más allá de lo que ha recomendado el docente. 
Una vía para lograr esa característica es la incentivación de una cualidad propia del ser humano, que da lugar a la invención y a la innovación: la creatividad, facultad humana que a lo largo de la historia ha despertado la atención de muchos estudiosos y desde diversas perspectivas, aunque a veces el hecho de ser creativo se asocia solo al arte y la literatura (Rius-Ulldemolins, Pecourt y Rubio, 2019).

Con frecuencia, la creatividad se usa en función de una tarea perpetua de los seres humanos: resolver problemas personales, familiares, laborales. Estas dos condiciones hay que tenerlas presentes en la formación universitaria, tanto en las ideas en torno a ella, como en su respectivo quehacer. No debe perderse de vista que "un problema es más una apuesta para tratar de descifrar algo y llegar a una conclusión parcial, que una tarea propuesta en la cual solo hay una respuesta posible" (Henao y Tamayo, 2014, p. 26). En la docencia los problemas son situaciones cognoscitivas que deben llevar a una respuesta (ya sea una afirmación, un argumento, una elaboración de un proceso o algoritmo para hacer algo) que el profesor debe prefigurar de modo tal que se ajuste a las características y posibilidades de los alumnos, pero a estos debe exigirles esfuerzos, por tanto, en general, es recomendable que no sea fácil, ni rápido su hallazgo. A los estudiantes hay que invitarlos y, más aún, conducirlos a reflexionar en torno a un asunto, a hacer una búsqueda bibliográfica o a experimentar de manera práctica, por eso el profesor debe pensar en las características del problema, para que esté al alcance de los estudiantes y para que los impulse a hallar la solución. De no tener en cuenta estos requisitos puede desilusionarlos y el efecto puede ser inverso al deseado.

La efectividad del empleo de los problemas en la formación universitaria puede ser mayor si incluyen la duda. Esta no es solo la suspensión del razonamiento para llegar a una determinación, ni la vacilación ante una decisión a tomar, ni la posposición de un asunto en aras de resolverlo o ventilarlo; en la formación universitaria la duda es valiosa si se concibe como un incentivo para continuar adelante en la búsqueda de nuevos conocimientos o en su confirmación. Cuando la duda incentiva el deseo de aumentar los conocimientos tiene un valor inestimable en la formación universitaria, por ello, es inteligente aprovecharla en el ejercicio de problematización y en la búsqueda de respuestas y soluciones a los problemas.

Debe quedar claro que el empleo de la duda y los problemas no es la panacea universal, pero propicia, en cierta medida, el aumento en el quehacer docente del activismo de los profesionales en formación; ambos, los problemas de contenido docente y las dudas, pueden vincularse con asuntos propios de la profesión (organizativos, salariales, de condiciones de trabajo, etc.) y desde aquí motivarlos a que se interesen por la sociedad, sus necesidades, dificultades, soluciones al alcance de la vista. Pero todo esto obliga al profesor a pensar mucho en la formulación de las preguntas, no solo para que sean claras y precisas, sino, sobre todo, para convertirlas en tareas, es decir, que fuercen a los estudiantes a razonar y crear soluciones, puede que no sean totalmente originales o nuevas, pero los ubica en la autopista de la creatividad, de la innovación, algo muy preciado en estos tiempos.

Valga reiterar que hoy en todo proceso de formación debe insistirse mucho más en lo referente a las preguntas, específicamente las que despiertan la curiosidad e inducen al estudiante a pensar y a crear. Cuando se habla de las interrogantes se tiene en cuenta no solo las del profesor hacia los alumnos (o 
sea, el profesional en formación), sino también las que los estudiantes hacen al docente; ambas variantes son valiosas de verdad si movilizan a los presentes en la actividad docente (alumnos y profesor). Este empeño encuentra una vía óptima en las tareas, de ahí que se invita a los profesores a que piensen en tareas que conduzcan a los estudiantes a formular preguntas que pueden encaminarse al docente, pero también a los otros alumnos.

No hay preguntas tontas ni respuestas definitivas; ante ellas el profesor deviene orientador. Ya no es una novedad afirmar que los docentes, cada vez más, tienen ese papel. En este caso específico significa que sea capaz de conducir a los estudiantes para que aprendan a preguntar de la mejor manera, del modo como se considera que es correcto. Es importante que el docente tenga sumo cuidado para que, cuando justiprecie las interrogantes, incluso aquellas que puedan parecerle ingenuas o mal formuladas, no castre algo que a veces está aparejado a la duda: la curiosidad.

Esa cualidad, la curiosidad, es valiosa tanto para el alumno como para el profesor $\mathrm{y}$, en el caso de este último, es provechosa no solo para enseñar, sino también para aprender, porque enseñando se aprende (Freire, 2010). Este razonamiento tiene hoy una importancia colosal debido a la gran cantidad y variedad de canales mediante los cuales los alumnos aprenden. Esta situación favorece que adquieran conocimientos que no están incluidos en el plan de clases, que el profesor no tiene por qué conocer y mucho menos dominar; así que puede suceder que acerca de algunos de esos temas los estudiantes sean los que enseñen al profesor, quien, si es inteligente, aprovecha la oportunidad, aumenta sus conocimientos y los diversifi- ca. Ahora bien, esta posibilidad, al mismo tiempo, hace más difícil el trabajo para los docentes.

Las acciones encaminadas a despertar la curiosidad dependen de muchos factores: la asignatura, el tema, el tipo de alumnos, las cualidades del profesor y, entre muchos más que pudieran mencionarse, el clima y el ambiente sociopolítico. En el raudal de opciones a la mano del docente para motivar inquietudes cognoscitivas en sus estudiantes está la diferenciación.

La diferencia establece el límite. Utilizar en la formación universitaria lo diferente no es solo hacer uso de lo diverso, sino también de las divergencias, de las discrepancias de criterios y de las fronteras entre estos; así se hace más ameno el quehacer formativo, más interesante, se enriquece y se vuelve más fructífero para los alumnos. No se trata solo de la diversidad interna del objeto de estudio, sino también de las maneras de comprenderlo, donde resultan destacables las oposiciones y, más aún, los antagonismos existentes entre los autores de tal o cual bibliografía o entre los profesores de la propia institución respecto a determinados problemas y a sus soluciones. El docente debe lograr que el alumno entienda que la opinión del profesor no es única y mucho menos infalible y eterna; con esta sinceridad y modestia estimula el deseo estudiantil de investigar y polemizar, cuyo resultado es el aumento del saber.

Ese "juego" con los contenidos permite atacar el aprendizaje exclusivamente memorístico, repetitivo. Ahora bien, esta afirmación no puede entenderse como rechazo categórico a la memorización, pues no pocas veces es necesaria, oportuna y hasta imprescindible; el quid del asunto está en que de ella no se haga un absoluto. 
En el mundo actual, con una frecuencia creciente, los estudiantes conducen al docente a dialogar, y este no debe frenarlos, sino aprovechar su insistencia; ahora bien, debe ser capaz de nutrirlo con el contenido a tratar y no irse de tema, ni caer en temáticas secundarias o inoportunas. No puede olvidarse el modo de pensar de los alumnos y sus otras características, sobre todo la edad. Ellos nunca van a desperdiciar una oportunidad para recrearse y eso lo pueden lograr con un tema de conversación que no los haga pensar tanto como, por ejemplo, la solución de un problema matemático, el análisis de una posición filosófica o la explicación de una estructura gramatical. Esta recomendación no significa que se desprecie la curiosidad o las dudas no relacionadas con el contenido que se desarrolla. Vale tener presente que "no se puede dialogar ignorando o silenciando las dudas de los interlocutores" (López, Pellón y Valdés, 2019, p. 8).

Se destaca en la realización de la formación activa e integradora que la clase se desenvuelva mediante diálogos. Estos tienen una gran importancia porque favorecen la interacción entre individuos y entre un individuo y un grupo -en este caso, de estudiantes (Gutiérrez-Fresneda, 2018). La docencia dialogada es una conversación, puede ser de coincidencia o divergencia de criterios, la cual puede transformarse en un debate porque haya discusiones e incluso polémicas. Cuando el profesor se propone realizar la docencia de manera dialogada, pone ante sí una tarea de extraordinaria actualidad: ampliar el quehacer formativo y hacerlo inclusivo. Ambas cualidades alcanzan un nivel elevado cuando es posible que en dicho proceso participen todos los actores de los procesos sustantivos de las instituciones formadoras (López, Pellón y Valdés, 2019), cada uno con sus responsabilidades.
En el quehacer formativo de hoy es difícil desarrollar una actividad con alta calidad si es unilateral, "no hay entendimiento que no sea comunicación e intercomunicación y que no se funda en la capacidad de diálogo" (Freire, 2010, p. 33). ¿Y será que hoy todos los docentes se proponen dialogar con sus estudiantes y llegan a cumplir su propósito?

El diálogo es valioso si desafía la capacidad creativa de los alumnos y de los profesores. No se trata de entablar una conversación amena sobre cualquier tema, sino de aquella que contribuye a la formación de los futuros profesionales, sobre todo que despierte en ellos la curiosidad, la indagación, mucho más importante si se relaciona con su vida profesional, que está por iniciarse.

De vital importancia en la formación universitaria es el desarrollo del pensamiento crítico de los estudiantes, que va aparejado al fortalecimiento de la independencia para la toma de decisiones, la autonomía para el aprendizaje, la formación de habilidades laborales, investigativas y comunicativas para la solución creativa de problemas profesionales, entre otras no menos importantes (León, Reiné y Charbonell, 2019).

El despliegue del pensamiento crítico se orienta a comprender y solucionar problemas, a evaluar alternativas y tomar decisiones; por tal razón, implica comprender, evaluar, e incluso, reflexionar acerca del pensamiento y de las conclusiones a las cuales se arribará. De aquí la importancia en la formación universitaria en cuanto a lograr profesionales aptos para someter a crítica cuanto sea necesario. Dicha formación es un marco óptimo para confrontar valores, prácticas, programas de aprendizaje, y para que el pensamiento crítico se refleje en la vida profesional del futuro especialista. Con este tipo de pensamiento se persigue que quien 
se está formando no se quede en las ideas, sino que también llegue a realizarlas, a partir de la posesión de los compromisos que tiene consigo mismo y con la sociedad. De aquí su importancia en el quehacer formativo y en el mundo profesional. Muchos docentes reconocen la importancia de desarrollar este tipo de pensamiento, pero pocos incorporan este objetivo a su quehacer formativo (Bezanilla, Poblete, Fernández, Arranz y Campo, 2018).

El pensamiento crítico puede confundirse con el pensamiento creativo, pero para que una persona llegue a ser un pensador crítico tiene que entender qué es un razonamiento de calidad, tener el compromiso pertinente para emplear con fundamentos sus conocimientos, para que el estudiante llegue a devenir un pensador crítico debe convertirse en un experto de sus conceptos "tiene que desarrollar la habilidad para mentalmente remover los conceptos ya establecidos para las cosas y probar ideas alternativas" (Mackay, Franco y Villacis, 2018, p. 340).

En la formación universitaria debe brindársele una atención cada vez mayor al ejercicio de la crítica. Este propósito puede centrarse en el contenido docente o ir más allá y abarcar la sociedad, sea mediante los asuntos del país o del acontecer internacional. Pero no ha de perderse de vista, como señalan los autores Suárez, Pabón, Villaveces y Martín (2018), que la actividad crítica no es solo un "ejercicio de pensamiento de alto orden, sino una búsqueda activa de retos y alternativas a los desafíos impuestos por la política, la dinámica social y las características de las generaciones actuales" (p. xviii).

Criticar no es condenar. Es improcedente identificar la crítica con la condena. Entenderla así sería reducir su significado y alcance; ella es la práctica del criterio y su finalidad es deslindar lo positivo de lo negativo, que es en sí rescribir, re-crear el contenido del texto que se lee desde la opinión del crítico, pero esta no es una simple opinión, su valor se debe no solo a que es un criterio individual, sino también a la posesión de una base objetiva que la sustenta. La crítica, contrario a lo que puede pensarse comúnmente, no parte solo de lo subjetivo, ni se encierra en sus marcos, antes bien, se fundamenta en la sociedad, en sus características y necesidades.

Respecto a la incentivación del pensamiento crítico en los profesionales en formación, debe brindársele una atención esmerada a los alumnos que se muestran impasibles ante lo que ocurre a su alrededor, no solo para que lo entiendan y, sobre esta base, para que critiquen o condenen, sino para que actúen a fin de hallar soluciones a los problemas y abrirle el paso a las transformaciones sociales, lo cual exige el concurso de todas las cualidades humanas, ante todo la integración de la razón y los sentimientos. En ello tiene gran valor el desarrollo de la sensibilidad humana.

La concepción de la formación activa e integradora que se expone en este trabajo tiene su base teórica en el pensamiento cubano de vanguardia, ante todo en las ideas de José Martí, quien de muchas maneras (explícita e implícitamente) y a lo largo de su copiosa obra escrita destacó la importancia del papel de los seres humanos en su educación (y, de hecho, en el proceso de formación). Uno de los muchos ejemplos que pueden sostener esta afirmación está dado por sus palabras siguientes: "Los tiempos están revueltos; los hombres están despiertos, y cada cual ha de labrarse con sus manos propias la silla en que se sienta al festín de la fortuna" (Martí, 1975 , t. 8, p. 284). 
La sociedad que se va abriendo a la humanidad mediante sus propias manos es de seres humanos emprendedores, creativos y con mente integradora. La formación universitaria será capaz de proveerle los profesionales acordes a tales características.

\section{La indiferencia: causas y esencia. La formación universitaria contra ella.}

Si se aprehende literalmente la palabra indiferencia puede entenderse como que no hay diferencia o que esta se niega, pero el significado recogido por varios diccionarios de la lengua española es estado de ánimo con el cual no se siente preferencia ni repulsión por nada, ni por nadie. No obstante, no falta quien hace uso del vocablo según la primera variante referida y sostiene que no significa desinterés, sino no establecer diferencia $y$, por tanto, amar del mismo modo a todo $\mathrm{y}$ a todos (Ramírez-Giraldo y Arrieta-Burgos, 2020). De cualquier manera, entendida de una u otra forma, más directa o más indirectamente, alude a la pasividad, la inactividad.

El crecimiento de la indiferencia es una de las particularidades de una sociedad que durante los primeros años del último cuarto del siglo XX comenzó a denominarse posmoderna, denominación que en la década de los ochenta refería, ante todo, a los países capitalistas desarrollados. Al pasar los años, muchas de sus características se han diseminado por todo el mundo y se han hecho propias sino de toda la humanidad, sí de una gran parte, entre ellas están el cuestionamiento y la deslegitimación de todo (ideas, principios éticos y políticos, aspiraciones sociales, etc.); el rechazo a la ideología y al humanismo de la Modernidad; la disensión; el principio vale todo, el individualismo en niveles superiores y, resultante de él, la pulverización social (Lyotard, 1990; Vattimo,
1990), la diseminación de la idea (que puede verse como un principio) de que cada cual viva su vida y los otros que se la arreglen como puedan y, el hecho de que la atención de cada cual recae sobre sí mismo.

El tema del ser humano en la sociedad posmoderna y del individualismo en la misma ha sido tratado por varios autores y desde diversas perspectivas. Uno de esos trabajos es el de la autora Silvia Molina (1990). En su texto saca a relucir el criterio de otros autores, entre ellos, el del sociólogo estadunidense Daniel Bel y del filósofo y sociólogo francés Jean Baudrillard. Entre las ideas que recoge del primero está que el advenimiento de la posmodernidad trae consigo la fragmentación social porque cada individuo solo persigue su autorrealización. Del galo señala, entre otras afirmaciones suyas, que, en una sociedad tan compleja, con tantas y muy varadas relaciones, donde lo permanente es el fluir, cada individuo solo pretende parecerse a sí mismo, porque en el mundo donde vive todo se lleva a las pantallas y se pierde la privacidad, ante lo cual a los seres humanos solo les queda ser pasivos e indiferentes.

Otras de las consideraciones interesantes que datan de esos años son de la autora española Adela Cortina (1990), quien asegura que el modo de pensar y sentir posmoderno se caracteriza, entre otros rasgos, por la fragmentación, el rechazo a armonizar lo universal y lo singular, optando por este último.

La acotación acerca del individualismo posmoderno estaría limitada si no portara algunas palabras de uno de los autores que más atención le brindó al tema: el filósofo y sociólogo francés Gilles Lipovetsky. En su libro La era del vacio. Ensayos sobre el individualismo contemporáneo (2000) asegu- 
ra que en la sociedad posmoderna prevalece la perspectiva neonarcisista, a través de la cual coinciden el individualismo y la miniaturización en el propósito de reducir la carga de las presiones sociales y expresa dos ideas que bien pueden ser una sola, que es una especie de compendio del problema que trata en dicho texto: "El ideal moderno de subordinación de lo individual a las reglas racionales colectivas ha sido pulverizado" (p. 7), o sea, cada cual se impone a los demás, pero dejando de atenderlos, es como si, a la manera de Husserl, los encerrara entre paréntesis y los ignorara. Seguidamente afirma que la individualización promovió y encarnó de manera masiva "un valor fundamental, el de la realización personal, el respeto a la singularidad subjetiva, a la personalidad incomparable sean cuales sean por lo demás las nuevas formas de control y de homogeneización que se realizan simultáneamente" (2000, p. 7). El individualismo se agigantó, pero en ese agrandamiento fue creciendo la desatención a lo ajeno y a lo social.

Como si eso hubiera sido poco, durante las dos últimas décadas del siglo $\mathrm{XX}$ crecieron el desencanto y la incertidumbre y se replegó la diversidad ideológica, no solo por la diseminación de las características mencionadas, sino también por un hecho histórico que tuvo lugar durante el empalme de las décadas de los ochenta y los noventa de la vigésima centuria: el derrumbe del socialismo europeo y con él, de lo que entonces se conocía como sistema socialista mundial, al que pertenecían países de Europa, Asia y América Latina. Esta debacle no fue solo el retorno al capitalismo de los estados europeos que formaban parte de dicho sistema político, económico y social, sino también un golpe contra la filosofía que lo sostenía teóricamente (el marxismo-leninismo) y contra la ideología (modo de ver a través de los diversos prismas: económico, político, artístico, jurídico, etc.) que se apoyaba en ella, lo cual, a su vez, provocó desilusión, desmovilización y titubeos en las fuerzas revolucionarias de todo el mundo que veían en esas sociedades el rumbo para arribar a niveles superiores de desarrollo social, cuya superioridad hallaban, ante todo, en las posibilidades que brindaba para resolver, con justeza, los problemas sociales.

A su vez, como asegura el filósofo cubano Pablo Guadarrama González (1998), en ese entonces parecía que para entrar a la posmodernidad (léase desarrollo) era imprescindible acogerse al "principio de la renuncia a todos los principios" (p. 181). En medio de ese torbellino de finales del siglo $\mathrm{XX}$, los defensores a ultranza del capitalismo reforzaron el discurso de la variedad de pensamientos, pero lo que sucedió en verdad fue la difusión del neoliberalismo, con la diáfana intención de renunciar a todas las otras variantes posibles de pensamiento y, paradójicamente, establecerlo como la ideología dominante, como el único pensamiento valedero, lo cual fue apuntalado por una idea que entraba en contradicción con dicha labor difusora: el final de las ideologías. En todo este fenómeno, la intención tácita era la detención de las ideas y argumentaciones críticas, las reivindicaciones populares y el olvido por decepción de la posibilidad de transformar la sociedad y construir una superior. Este ideal comenzó a verse como una quimera, como algo totalmente irrealizable, a lo cual contribuyó la pérdida de interés por el futuro y el pasado, que se hizo acompañar por la atención centrada en el presente como un asunto únicamente individual.

Ese terreno fue fértil para el crecimiento del pesimismo y para la renuncia a la crítica y al optimismo (Roig, 1993), así como para la germinación de la indiferencia, que, al de- 
cir de la autora Silvia Molina (1990), "no significa que no se hace nada, sino que todo puede cohabitar" (p. 45).

Ahora bien, la indiferencia es al mismo tiempo carencia de imaginación y sueños, incapacidad para desplegar utopías y lo cierto es que, como asegura el intelectual uruguayo Mario Benedetti, "una generación sin utopías será siempre una generación atascada (aunque tenga la obsesión de la velocidad) e inmóvil (aunque se agite sin cesar)" (1992, p. 80). He aquí el porqué de la preocupación respecto a los estudiantes del nivel superior y a la formación universitaria.

La sociedad humana de principios del siglo XXI, movida en gran medida por el mercado y los medios de difusión masiva, muestra la tendencia a que se mate el interés por el futuro y solo se piense en el presente y que se haga únicamente, o, por lo menos, sobre todo, desde la perspectiva individual. Tal circunstancia propicia la indiferencia (indolencia, insensibilidad), que al parecer se va afianzando como rasgo característico no solo de los jóvenes, pero sí predominantemente de ellos. En ese grupo social, según el autor Ávila (2015), en las sociedades democráticas contemporáneas, se observa un distanciamiento hacia el sistema político y falta de confianza en él, a partir de lo cual señala "la apatía y la pasividad de las nuevas generaciones cuando se trata de asuntos concernientes con la esfera pública, al menos en su dimensión más institucional" ( $\mathrm{p}$. 102). Actualmente la indiferencia se observa de manera creciente y no solo en las generaciones más nuevas; se halla en personas de diversas edades y con independencia de especificidades individuales, como el sexo, el nivel cultural, el lugar de residencia.

Una de las causas fundamentales del crecimiento de la indiferencia es la influen- cia que ejerce la ideología liberal fatalista, inmovilizadora, la cual "con aires de posmodernidad, insiste en convencernos de que nada podemos hacer contra la realidad social que, de histórica y cultural, pasa a ser o a tornarse "casi natural"" (Freire, 2010, pp. 18-19). Dicha ideología engendra pasividad, resignación ante la sociedad y los seres humanos, porque a estos, según sus ideólogos, no es posible transformar, ni siquiera en forma superficial. De tal suerte, es un absurdo, o cuando menos una quimera, pensar en el mejoramiento humano. Y lo más preocupante no es que tales posiciones se limiten a los argumentos de los ideólogos que la sostienen y desarrollan, sino que se observa, con una frecuencia creciente, en personas a todas luces desconectadas de las lecturas ideologizantes.

Ese fenómeno resulta ser preocupante, a su vez, porque muchos de los que lo padecen, lo niegan, rechazan la probabilidad de que se puede convertir en un problema social, pero, sobre todo, porque sostienen que no es necesario preocuparse por la disminución del compromiso con la sociedad, con la patria y con los otros seres humanos, porque estos asuntos pertenecen al pasado.

Para atacar la indiferencia es necesario tomar conciencia de que en la sociedad hay un número de personas indolentes que va siendo cada vez más impactante. Al mismo tiempo, hace falta tener presente que el mundo exige atención, para entenderlo y para actuar sobre él. El profesional en formación debe prepararse óptimamente como tal, pero esto ha de incluir el contexto social, para comprenderlo y transformarlo si es preciso, a fin de que sea beneficioso para los seres humanos.

Si la indiferencia se observa con profundidad y detenimiento, se puede entender que 
va aparejada a la humillación y la desmoralización (Salazar y Heinrich, 2015), y al mismo tiempo se puede tomar conciencia de un peligro que pende sobre la humanidad: que llegue a ser vista como una cualidad humana "natural" y así deje de llamar la atención; de este modo puede llegar a ser indiferente. Si el fenómeno se mira con una visión "catastrofista" puede pensarse en la posibilidad de que sea vista como una cualidad buena, favorable y devenga un valor.

Hoy urge pensar, con ímpetu, en dicho comportamiento, para revertirlo en su contrario: el entusiasmo, el anhelo vehemente, el interés; o, por lo menos, para aminorarlo. Los hombres y las mujeres del siglo XXI tienen todavía la posibilidad de impedir que la indolencia devenga una característica esencial suya y, peor aún, que las generaciones de esta centuria sean caracterizadas en el futuro como indiferentes a la indiferencia.

La formación universitaria es un marco que brinda grandes posibilidades para atacar el incremento de esa manera de ser. Pero es necesario que el quehacer formativo se aborde con amplitud mental, deseo innovador e intenciones integradoras. Así, puede proponerse como objetivo el desarrollo de la sensibilidad humana y con ella, el propósito de acabar con la separación esquemática y el alejamiento, entre la razón y la afectividad.

Para atacar esa separación tiene grandes posibilidades el gusto estético. Esta afirmación se basa en que este no carece de racionalidad, aun cuando desde él la respuesta que tiene mayor peso es afectiva. La potencialidad integradora de lo estético (incluido el mencionado gusto) se debe, entre otros factores, a que "la experiencia estética reúne y pone de acuerdo (...) distintas facultades humanas" (Pérez, 2018, p. 62), ya que, por ejemplo, la poesía, con toda su carga estéti- ca que se encamina directamente a lo afectivo "tiene el poder de conectarnos, de modo personal y auténtico, con las verdades más escurridizas" (Billitteri, 2018, p. 121).

El trabajo de formación universitaria no es solo proporcionar conocimientos a los estudiantes, ni orientarlos en su construcción o suministrarles métodos y vías para ello, incluye la acción sobre todos los otros aspectos propios del ser humano. No solo es valiosa la preparación científica que tengan los docentes; la valía de los profesores es mucho mayor si su formación como profesional es integral.

No existe el observador imparcial; en toda reflexión y en toda obra (incluida la formación universitaria) hay carga ética, sobre todo responsabilidad con la sociedad. Una de las tareas claves de la formación universitaria es tener presente en todo momento que a quienes se está formando son seres sociales que viven en una comunidad y deben dialogar con ella (Ferrada-Sullivan, 2017). Sobre esta base, es importante tener presente que los profesionales deben formarse no solo para que posean excelentes capacidades como especialistas, con aptitudes de primer nivel en cuanto a su profesión, sino también para que sean seres humanos de alta calidad $\mathrm{y}$ esto incluye la sensibilidad humana.

Más que una estrechez, es una lástima concebir la formación universitaria, al decir de Freire (2010), como un "adiestramiento técnico" (p. 30), pues al entenderla de este modo, apuntaba este autor, de ella se mata su esencia, es decir, "su carácter formador" (p. 30), ante todo para que quien se está formando actúe en bien de la humanidad.

Tanto la formación activa e integradora, como el quehacer encaminado a atacar la indiferencia, deben estar unidos a las ideas y acciones educativas. Valga insistir en algo 
que parece una verdad de Perogrullo, repetido con una frecuencia que puede llegar a ocasionar hastío, pero que no se concreta en la práctica, por lo menos con sistematicidad y es que en el proceso de formación, los futuros profesionales deben desarrollar su intelecto y su afectividad y con ello, tomar consciencia de su responsabilidad para formarse como hombres y mujeres responsables, capaces de detectar los problemas sociales, analizarlos y tomar decisiones adecuadas sobre ellos. Al arremeter contra la indiferencia, también se ha de embestir al individualismo feroz de los tiempos que co- rren. No es disolver al individuo en el colectivo, ni sobrevalorar a este último, es darle a cada uno la importancia adecuada.

Este quehacer, con el cual se busca formar seres humanos íntegros y activos socialmente, queda incompleto si no ataca y vence la indiferencia y la pasividad ante los males sociales y si no logra activar a los estudiantes en pos de la construcción de un futuro mejor, acción que ha de llevar a cabo con el concurso de todas sus facultades, porque es una obra de inteligencia y amor. En este modo de entender la formación universitaria es decisivo el despliegue de la sensibilidad humana.

\section{Conclusiones}

La formación universitaria no debe limitarse a formar a un profesional con competencias y cualidades estrictamente de la profesión. En el quehacer formativo ha de ser central el propósito de formar a los estudiantes como seres humanos con cualidades superiores, es decir, todas aquellas, posibles según las condiciones históricas, que los hagan más humanos.

El objetivo de enriquecer la formación universitaria con la finalidad de formar seres humanos compagina con el modo de concebirla como activa e integradora, en cuanto se basa en el modo de comprender al ser humano como un todo complejo, con caracteres antagónicos que se observan de forma integrada.

En la formación universitaria activa e integradora tiene un lugar fundamental el desarrollo de la sensibilidad humana, categoría que hace referencia a la unión de la razón y la afectividad, así como a la activación del ser humano en pos de la solución de problemas, sobre todo de aquellos propios de la sociedad.
La bibliografía existente, cada vez más numerosa, en torno a la afectividad y temas afines, demuestra que en los círculos académicos y científicos aumenta el reconocimiento de su importancia.

La concepción de formación universitaria activa e integradora tiene grandes posibilidades para atacar la indiferencia. Para que estas posibilidades se realicen, es imprescindible que el quehacer formativo se aborde con amplitud mental, deseo innovador e intenciones integradoras, pero no solo con esas características; valerosa es, asimismo, la categoría sensibilidad humana, por su consubstancialidad activadora e integrista, un lugar central y priorizado desde donde se insiste en la conjugación de la razón y la afectividad y el enfrentamiento a la indiferencia.

La categoría sensibilidad, por su esencia activadora e integrista, puede jugar un rol importante en la realización del objetivo de formar a los hombres y las mujeres que requiere la humanidad en su andar rumbo al futuro más cercano. 


\section{REFERENCIAS BIBLIOGRÁFICAS}

Ávila, R. (2015). El dispositivo de formación cívica y ética desde los planteamientos de Michel Foucault: prácticas y discursos en la División Académica de Educación y Artes de la UJAT (20122014). Uni-pluriversidad, 15 (1), 100-110. https://revistas.udea.edu.co/index.php/unip/article/ view/23652/19428

Balladares, J., Avilés, M., y Pérez, H. (2016). Del pensamiento complejo al pensamiento computacional: retos para la educación contemporánea. Sophia, Colección de Filosofía de la Educación, 21, 143-159 http://www.redalyc.org/articulo.oa?id=441849209006

Benedetti, M. (1992). "El capitalismo ha ganado un partido, pero no el campeonato", 77-83, En Interrogantes de la Modernidad, La Habana: Edición Tempo.

Bezanilla, M., Poblete, M., Fernández, D., Arranz, S., y Campo, L. (2018). El Pensamiento Crítico desde la Perspectiva de los Docentes Universitarios. Estudios Pedagógicos, 44(1), 89-113. http:// revistas.uach.cl/index.php/estped/article/view/3600/4473

Billitteri, S. (2018). Hannah Arendt lectora de Franz Kafka: una mirada pedagógica a la razón poética. Teoría educativa, vol. 30, no.1, 117-132. https://revistas.usal.es/index.php/1130-3743/article/ view/teoredu301117132

Bisquerra, R. (2005). La educación emocional en la formación del profesorado. Revista Interuniversitaria de Formación del Profesorado, (54), 95-114 https://dialnet.unirioja.es/ejemplar/143760

Bodei, R. (1995). Geometría de las pasiones. México: Fondo de Cultura Económica.

Cortina, A. (1990). Ética sin moral. Madrid: Tecnos.

Cruz, J., Pérez, A., Torralba, A., y Bonilla, B. (2017). Puebla, México, “Ciudad Patrimonio de la Humanidad". Percepción ciudadana. International Journal of Scientific Management and Tourism, 3(2), 273-298. https://dialnet.unirioja.es/servlet/articulo?codigo=6132923

Cuadra-Martínez, D., Castro, P., y Juliá, M. (2018). Tres saberes en la formación profesional por competencias: integración de teorías subjetivas, profesionales y científicas. Formación Universitaria, 11(5), 19-30, http://dx.doi.org/10.4067/S0718-50062018000500019

Cuervo, L. (2017). Formar para la participación democrática. Caminos de la educación para la paz. Reflexiones sobre la educación para la paz, condiciones legales y construcción de estrategias de formación de la participación ciudadana en la escuela. Uni-pluriversidad, 17(2), 39-46. https:// revistas.udea.edu.co/index.php/unip/article/view/334006

Descartes, R. (2011). Discurso sobre el método que ha de seguir la razón para buscar la verdad en las ciencias. Historia de la filosofía, tomo 3. La Habana: Félix Varela.

Díaz, S. (2013). Reflexión filosófica de la educación. Buenos Aires: Dirección general de cultura y educación.

Duarte, J., y Valbuena, E. (2014). Referentes de la formación de profesores en educación ambiental. Revisión de antecedentes 2000-2012. Uni-pluriversidad, 14(2), 27-36 https://revistas.udea.edu. co/index.php/unip/article/view/20054 
Ferrada-Sullivan, J. (2017). Reflexiones preliminares para pensar la formación de formadores en la universidad moderna: Nuevas miradas y nuevos diálogos desde la complejidad. Revista Electrónica Educare, 21(2): 1-17. doi: http://dx.doi.org/10.153

Freire, P. (2010). Pedagogía de la autonomía y otros textos. La Habana: Editorial Caminos.

García, J. (2014). La razón sensible, más allá de la razón ética. Un fundamento epistemológico para el enfoque CTSA. Uni-pluriversidad, 14(2), 11-15. https://revistas.udea.edu.co/index.php/unip/ issue/view/1774

García, J. (2018). ¿Para qué educar? Uni-pluriversidad, 18(1), 11-12. https://revistas.udea.edu.co/ index.php/unip/issue/view/3064

Guadarrama, P. (1998). Humanismo, marxismo y posmodernidad. La Habana, Cuba: Editorial de Ciencias Sociales.

Gutiérrez-Fresneda, R. (2018). Las destrezas del pensamiento y el aprendizaje compartido para la mejora de la composición escrita. Estudios sobre Educación, 34, 263-281 https://revistas.unav. edu/index.php/estudios-sobre-educacion/article/view/7212/17459

Henao, J., y Tamayo, O. (2014). Enseñanza y Aprendizaje del concepto naturaleza de la materia mediante la resolución de problemas, Uni-pluriversidad, 14 (3), 25-45. https://revistas.udea.edu.co/ index.php/unip/article/view/21335/17735

Lapoujade, M. (1988). Filosofía de la imaginación. México: Siglo xxi.

León, Y., Reiné, Y., y Charbonell, M. (2019). Una mirada a la formación de profesionales universitarios que demanda el siglo XXI en Cuba. Revista Cubana de Educación Superior, 38(1), 1-13. http://scielo.sld.cu/pdf/rces/v38n1/0257-4314-rces-38-01-e11.pdf

Loaiza-Zuluaga, Y., Taborda-Chaurra, J., y Ruiz-Ortega, F. (2020). La pedagogía: Una mirada de estudiantes y profesores de programas de Licenciatura. Revista Colombiana de Educación, 1(79), 13-38. https://doi.org/10.17227/rce.num79-8084

López, A., Pellón, R., y Valdés, F. (2019). La filosofía como problematización dialógica. Una reflexión desde la universidad. Revista Cubana de Educación Superior, 38(1), 1-14. http://www. rces.uh.cu/index.php/RCES/article/view/254

Lyotard, J.-F. (1990). La condición posmoderna. México: Red Editorial Iberoamericana (REI).

Lipovetsky, G. (2000). La era del vacío. Ensayos sobre el individualismo contemporáneo. Barcelona: Editorial Anagrama.

Mackay, R., Franco, D., y Villacis, P. (2018). El pensamiento crítico aplicado a la investigación. Universidad y Sociedad, 10(1), 336-342. http://rus.ucf.edu.cu/index.php/rus

Maldonado, C. (1999). Visiones sobre la complejidad. Bogotá: El Bosque.

Matías, A., y Fernández, O. (2018). Desafíos epistemológicos de la educación superior en el siglo xxi. Cadernos de Pesquisa, 25(1), 11-22 DOI: http://dx.doi.org/10.18764/2178-2229v25n1p11-22

Martí, J. (1975). Obras Completas. La Habana; Editorial de Ciencias Sociales.

Martins, I. P. (2014). Políticas Públicas e Formação de Professores em Educação CTS. Uni-pluriversidad 14(2), 50-62. http://aia-cts.web.ua.pt/artigo.pdf 
Marx, C. (1973). Tesis sobre Feuerbach. Obras Escogidas de Marx y Engels, tomo 1. Moscú: Progreso.

Minkevicius, Y. (1988). En busca de la definición íntegra del hombre. Problemas del mundo contemporáneo, (115), 140-150.

Molina, S. (1990). El hombre en la perspectiva posmoderna. Revista Estudios Políticos, (4), 37-50. http://dx.doi.org/10.22201/fcpys.24484903e.1990.4.59835

Montañez, C., y Suárez, M. (2019). Conceptualización de la formación profesional para la educación inclusiva. REIIE. Revista Electrónica de Investigación e Innovación Educativa, (1), 125-140. http://cresur.edu.mx/OJS/index.php/CRESUR_REIIE/article/view/320

Morin, E. (1999). Los siete saberes necesarios para la educación del futuro. París: UNESCO,

Morin, E. (2012). La cabeza bien puesta. Repensar la reforma. Reformar el pensamiento. Buenos Aires: Nueva Visión.

Nieto, F., y Somuano, F. (2020). Participar o no participar: análisis tipológico de la participación ciudadana de los mexicanos. Revista de Ciencia Politica, 40(1), 49-72 http://dx.doi.org/10.4067/ S0718-090X2020000100049

Pacheco, M., y Pupo, R. (2017). José Martí, la educación como formación humana. La Habana: Centro de Estudios Martianos.

Pérez, J. (2018). La formación del gusto como paradigma de la educación personalizada. Estudios sobre Educación, 34, 47-65. https://revistas.unav.edu/index.php/estudios-sobre-educacion/article/view/9687

Pérez, J. (2018). La formación de maestros para la enseñanza del lenguaje como práctica social. Uni-pluriversidad, 18(1), 36-46. https://doi.org/10.17533/udea.unipluri.18.1.04

Ramírez-Giraldo, C., y Arrieta-Burgos, E. (2020). Sartre, lector del estoicismo: a propósito de la asunción y la libertad. Revista Lasallista de Investigación, 17(1): 389-402 https://doi.org/10.22507/rli. v17n1a12

Ramos, G. (2006). La formación humanística como componente de la formación integral del profesor universitario. Revista Educação em Questão, 27(13), 7-27 https:/www.google.com/url?sa=$\mathrm{t} \& \mathrm{rct}=\mathrm{j} \& \mathrm{q}=\& \mathrm{esrc}=\mathrm{s} \&$ source $=$ web $\& \mathrm{~cd}=\& \mathrm{ved}=2 \mathrm{ahUKEwiN \_ uvfra7wAhUBheAKHVStB6UQ}-$ FjAAegQIAhAD\&url=https $\% 3 \mathrm{~A} \% 2 \mathrm{~F} \% 2 \mathrm{Fperiodicos}$.ufrn.br\%2Feducacaoemquestao $\% 2 \mathrm{Farti}-$ cle\%2Fdownload\%2F4489\%2F3673\%2F\&usg=AOvVaw1IfIGxw_Fcnntnw9zySxUa

Roig, A. (1993). La concepción de la historia en el desarrollo de nuestro pensamiento: respuestas a los posmodernos desde América Latina. Islas, (105), 3-26.

Ronquillo, L., Cabrera, C., y Barberán, J. (2019). Competencias profesionales: desafíos en el proceso de formación profesional. Opuntia Brava, 11, (monográfico especial), 15-40. http://opuntiabrava. ult.edu.cu/index.php/opuntiabrava/article/view/653

Rius-Ulldemolins, J., Pecourt, J., y Rubio, J. (2019). Contribución al análisis sociológico de la creatividad y la digitalización del campo cultural: creación, intermediación y crisis. Arbor, 195(791): a491, 1-18. http://arbor.revistas.csic.es/index.php/arbor/article/view/2305 
Rousseau, J. (2011). Discurso sobre el origen de la desigualdad. Historia de la Filosofía, tomo 4. La Habana, Cuba: Félix Varela.

Ruiz, A. (1955) Humanismo y sobrehumanismo. Madrid, España: Aguilar.

Salazar, R., y Heinrich, M. (2015). Maldad, odio, indiferencia y vaciamiento del reservorio moral en la sociedad contemporánea. Revista Conjeturas Sociológicas https://revistas.ues.edu.sv/index. $\mathrm{php/conjsociologicas/article/view/105}$

Suárez, J., Pabón, D., Villaveces, L., y Martín, J. (2018). Pensamiento crítico y filosofía. Un diálogo con nuevas tonadas. Barranquilla: Universidad del Norte http://www.fundacionpromigas.org.co/ es/Biblioteca/Documents/Libros/ePensamiento\%20cr\%C3\%ADtico\%20y\%20filosofia.pdf

Vattimo, G. (1990). En torno a la posmodernidad. Barcelona: Anthropos.

Vázquez, A. (2014). Enseñanza, Aprendizaje y Evaluación en la Formación de Docentes en Educación CTS en el contexto del siglo XXI. Uni-pluriversidad, 14(2), 37-49 https://revistas.udea.edu. co/index.php/unip/article/view/20055/16945

Vázquez, J., Hernández, J., Vázquez-Antonio, J., Juárez, L., y Guzmán, C. (2017). El trabajo colaborativo y la socioformación: un camino hacia el conocimiento complejo. Revista Educación y Humanismo, 19(33), 334-356 DOI: http://dx.doi.org/10.17081/eduhum.19.33.2648

Velásquez, C. (2016). La formación en investigación de los docentes universitarios. Estudio de caso en una Institución de Educación Superior Colombiana. Uni-pluriversidad, 16(1), 15-25 https:// revistas.udea.edu.co/index.php/unip/article/view/326181

Zabalza, M. (2011). Formación del profesorado universitario: mejorar a los docentes para mejorar la docencia. Educação, Santa Maria, 36(3) 397-424. https://core.ac.uk/download/pdf/231121713. pdf

Zambrano, M. (1939). Pensamiento y poesía en la vida española. México: Fondo de Cultura Económica. 